\title{
Configurações
}

Revista de sociologia

\section{Caminhos desobedientes: pensar criticamente o contexto português de conhecimento}

Wayward paths: critical thinking in the Portuguese context of knowledge Chemins désobéissants: envisager de forme critique le contexte portugais de la connaissance

\section{Sheila Khan e José Carlos Morgado}

\section{OpenEdition}

Journals

\section{Edição electrónica}

URL: http://journals.openedition.org/configuracoes/2014

DOI: 10.4000/configuracoes.2014

ISSN: 2182-7419

\section{Editora}

Centro de Investigação em Ciências Sociais

\section{Edição impressa}

Data de publição: 1 Dezembro 2013

Paginação: $75-88$

ISBN: 1646-5075

ISSN: 1646-5075

\section{Refêrencia eletrónica}

Sheila Khan e José Carlos Morgado, « Caminhos desobedientes: pensar criticamente o contexto português de conhecimento », Configurações [Online], 12 | 2013, posto online no dia 08 outubro 2014, consultado o 01 maio 2019. URL : http://journals.openedition.org/configuracoes/2014; DOI : $10.4000 /$ configuracoes.2014

Este documento foi criado de forma automática no dia 1 Maio 2019. 


\title{
Caminhos desobedientes: pensar criticamente o contexto português de conhecimento
}

\author{
Wayward paths: critical thinking in the Portuguese context of knowledge \\ Chemins désobéissants: envisager de forme critique le contexte portugais de la \\ connaissance
}

\section{Sheila Khan and José Carlos Morgado}

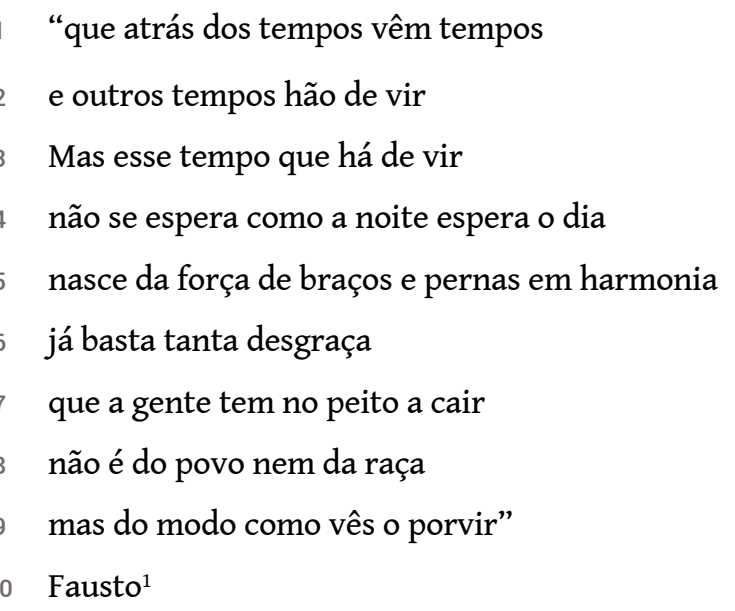

\section{Pensar criticamente as Epistemologias do Sul}

11 A tradição de um pensamento crítico sobre as Epistemologias do Sul não é de todo atual. No entanto, uma certa cautela no que toca à existência das várias experiências de 'Sul' torna necessário pensar-se estas Epistemologias dentro de vários contextos históricos, culturais, sociais, políticos e até mesmo circunstanciais. Se refletir sobre as consequências da modernidade e colonialidade de timbre eurocêntrico se traduz para uns na ideia de 
uma hierarquia de conceção ontológica (Maldonaldo-Torres, 2007), para outros traduz-se na urgência de refutar esta hegemonia eurocêntrica e resgatá-la de um certo epistemicídio de saberes e conhecimentos válidos para a compreensão de uma ontologia universal do mundo (Meneses, 2012; Khan, 2011; Martins et al., 2012; Martins, 2013). A binarização do universo das experiências humanas, sedimentada, por um lado, na exposição menosprezante e inferiorizada de uns e, por outro lado, na elaboração sofisticada de outros, tem sido o húmus para melhor sentir, interpretar e auscultar a importância das Epistemologias do Sul no interior de um pensamento predominantemente ocidental, que na verdade e de acordo com o pensamento de vários autores, entre eles o do sociólogo Boaventura de Sousa Santos, é "um pensamento abissal" que "Consiste num sistema de distinções visíveis e invisíveis, sendo que as invisíveis fundamentam as visíveis. [...] que dividem a realidade social em dois universos distintos: 0 universo 'deste lado da linha' e o universo 'do outro lado da linha”' (Santos, 2007: 3). As Epistemologias do Sul surgem como um movimento de intervenção e de reflexão sobre realidades subjugadas e subordinadas a uma lógica e retórica asfixiantes, no interior das quais não existe lugar para o diverso. Se o Sul, como metáfora de subalternização, de esvaziamento existencial e de despojamento moral do Outro, por um lado, traz a força de uma filosofia e de uma prática de emancipação, por outro lado, esta mesma força é também canalizada para uma análise cuidadosa e vigilante dos contextos históricos e políticos, que continuam a produzir, legitimar e naturalizar os lados humanos abissais no mundo, quer através da experiência da expansão marítima, do colonialismo, do imperialismo e da modernidade (ver Dussel, 2000), quer através dos fenómenos de neocolonialismo e neoimperialismo que pretendem legitimá-la e, por conseguinte, preservar esta situação de subalternidade geopolítica como normativa e inexpugnável (Mignolo, 2007). Na verdade, "as múltiplas e heterogéneas estruturas globais", que imperaram durante séculos, não se esfumaram com a mera eliminação das administrações coloniais, nem com a consequente "descolonização jurídico-política da periferia ao longo dos últimos 50 anos" (Lopes, 2009: 123).

Salientar esta situação a nível global implica, em simultâneo, trazer o nosso olhar para questões que se prendem não apenas com os jogos de poder económico e político, mas também com decisões totalitárias que suprimem saberes e conhecimentos que à luz de uma arrogância ocidental são brutalmente rasurados da diversidade cognitiva do mundo humano. Nesse sentido, tentativas de superar este "fascismo epistemológico" (Santos, 2008), e na mira de encontrar resposta às assimetrias e confrontos nas práticas e nas auto e heterorrepresentações do Norte global versus o Sul global, têm sido avançadas por diversos posicionamentos. Enquanto as teorias do crescimento e modernização neoliberais (Rostow, 1964; Hoselitz, 1960) assumem que os países do Sul sofrem de atraso e, como tal, para se desenvolver devem reproduzir por difusão a lógica e o modelo económico, cultural e político dos países do centro, as teorias neoinstitucionais (Myrdal, 1974) criticam a receita neoliberal e advogam uma corretora mas suave intervenção do Estado de modo a minorar as assimetrias do mercado, mas sem questionar nem a economia de mercado, nem a natureza do Estado. Por seu turno, as teorias da dependência (Frank, 1961; Furtado, 1961) e do centro-periferia (Wallerstein, 1990; Santos, 1985) assumem que o dito subdesenvolvimento do Sul é o resultado da lógica da dominação secular dos países/regiões-satélite por parte das metrópoles coloniais e póscoloniais. 
Embora sujeita a eventuais correções ou refinamentos, consideramos que estas últimas teorias são heuristicamente mais fecundas para compreender e explicar os fossos socioeconómicos, os alheamentos e distanciamentos históricos e os discursos simbólicoculturais legitimadores da arrogância ocidental em relação aos países do Sul. O quadro atual de investigação mostra-nos várias propostas que refutam a hegemonia ocidental do saber, validando outros caminhos teóricos e metodológicos que são reconhecidos como instrumentos de conhecimento de igual valor analítico da experiência do mundo humano (Meneses, 2012; Khan, 2011; Martins et al., 2012; Martins, 2013). Santos (2011) chama a atenção para a premência de uma maior vigilância epistemológica face à existência de um colonialismo que, no plano epistemológico, tem vindo a "manifestar-se de uma forma virulenta ao atribuir o monopólio do conhecimento válido à ciência moderna e à filosofia ocidental. Assim se desvalorizam, suprimem ou marginalizam outros conhecimentos" (Santos, 2011: 146). Este esforço epistemológico de 'descolonizar a Europa' não é uma tentativa isolada, pois outras reflexões recentes vêm transmitindo e tentando sedimentar este exame crítico da hegemonia do modelo e do pensamento ocidental (Harding, 2000; Hountondji, 2002; Silva e Cardoso, 2005; Cassano, 2010; Mignolo 2011). No plano mais amplo da investigação atual, outras propostas têm sido lançadas sob uma pluralidade operacional de designações, como, por exemplo: emancipatory knowledge (Oliver, 1997; Barnes, 2003), epistemic desobedience (Mignolo, 2009), Southern theory (Connell, 2007), subaltern global sociology (Burawoy, 2008), provincializing Europe (Chakrabarty, 2000), decolonizing methodology (Smith, 1999) e Epistemologias do Sul (Santos e Meneses, 2009).

No contexto português, o não reconhecimento de outros conhecimentos é ainda fruto de um enviesamento político-ideológico e cultural. Afirmá-lo desta maneira significa pensar que a reflexão histórica de Portugal sobre si, sobre a sua posição semiperiférica, sobre o seu imaginário quase compulsivo e desesperado como membro de um Norte global resultou numa tradição de esquecimento, de incapacidade de se olhar, na medida em que a ferida colonial e imperial empurra esta nação para uma incessante distração dos seus problemas e dos seus questionamentos interiores. Na verdade, como observa Eduardo Lourenço: "assim, no mais profundo deles mesmos, europeizados empiricamente, como nunca o foram, os portugueses não se percebem espontaneamente como 'europeus', senão quando a Europa os percebe superlativamente como portugueses" (Lourenço, 2011: 109-110); não obstante este facto, "de um certo modo, em Portugal, como nos outros países do Ocidente, tudo já está escrito em europeu" (ibid.: 110). Por conseguinte, descolonizar a história, produzir conhecimento e saber aceitar (Lander, 2000) outros saberes e grelhas de análise ergue-se como um passo significativo para pensar e criticamente posicionar a relevância das Epistemologias do Sul no contexto português de investigação.

\section{A descolonização do pensamento}

O desafio que se coloca é então saber como descolonizar o pensamento e a produção de conhecimento, no espaço e tempo da nossa investigação em Portugal. Sandra Harding, num trabalho intitulado "Should philosophies of science encode democratic ideals?" (2000), lança, no nosso entender, uma provocação no que concerne à crença de que atrás da democratização do saber vêm a promoção e o diálogo entre diferentes conhecimentos. Para a autora, pode ser falaciosa esta crença, na medida em que oculta, mediante uma nova e sedutora nomenclatura e linguagens científicas, a tendência para uma soberania 
de uns saberes em detrimento de outros. Nesse sentido, argumenta Harding, "a busca de ideais universais limita a diversidade cognitiva que é e sempre foi uma fonte importante de crescimento do saber" (Harding, 2000: 134). Por isso, na mesma linha de pensamento, torna-se necessário avaliar os contextos históricos e culturais de produção de conhecimento, pondo de lado hierarquias de capacidade de produção de conhecimento, incessantemente criados pelas grandes instituições e universidades do Norte global.

Esta propensão de mascarar a democracia epistemológica no contexto português de investigação com grandes e apelativos chavões, como multiculturalismo, pós-colonialismo e diversidade cultural, não é senão uma outra forma de dizer e de validar a hegemonia ocidental no modo como vê e organiza a História e as narrativas de outros povos e culturas. Num projeto coordenado por Marta Araújo e Sílvia Maeso, sobre "Raça e África em Portugal: um estudo sobre manuais escolares de história", as investigadoras (Araújo e Maeso, 2010, 2011, 2013) constataram que:

a narrativa central dos manuais escolares de história é constituída por um discurso evasivo de raça/poder. A naturalização de certos processos, que ajudaram a constituir as relações de poder contemporâneas, conduziram à formação de quadro interpretativos ideológicos. Esta evasão é crucial para compreender que para alcançar uma pedagogia e um ensino mais crítico da história (bem como de outras disciplinas) se terá de ir além da inclusão de outras perspectivas e versões da história, e evidenciar antes a produção de interpretações históricas mais críticas e informadas (Lesko; Bloom, 1998). Por exemplo, se o colonialismo, a escravatura, a cristianização e a nacionalização forem entendidas como um processo "natural" naqueles tempos, como podem os estudantes obter um conhecimento historicamente contextualizado de noções como segregação, raça ou minoria étnica nas sociedades contemporâneas [...]?; se o racismo não for amplamente discutido no contexto do esclavagismo colonial e da segregação moderna, como poderão interpretar o "racismo nos jogos de futebol" [...]? se a imposição da civilização sobre os povos indígenas americanos não for analisada criticamente, como podem os estudantes compreender que "[...] o terrorismo tem vindo a tornar-se numa ameaça para o mundo cada mais globalizado, assumindo hoje objectivos civilizacionais ao pretender a afirmação de uma cultura em detrimento do enfraquecimento ou até a destruição de outra [...]", como relacionado com o 11 de Setembro e a Guerra no Iraque?

No Portugal democrático, (pós)colonial, os manuais escolares continuam a sublinhar uma imaginação imperial que apenas considera como cidadãos os seus nacionais, ajudando a reforçar e a reproduzir a ideia de semelhança (Araújo e Maeso, 2010: 258-259).

Os silêncios da História de outros povos permanecem num espaço de esquecimento histórico e pedagógico desta nação que se imagina e se narra como europeia, moderna e pós-colonial. Este é apenas um exemplo a aflorar. No entanto, a montante do conhecimento sedimentado pelos manuais escolares, encontramos um outro ainda mais problemático que se prende com o que subjaz à definição e criação dos curricula (Morgado, 2003, 2004, 2013).

\section{O papel do currículo na (des)colonização do conhecimento}

Como artefacto social, político e cultural, o currículo não é neutro nem inócuo. A relação simbiótica que mantém com o conhecimento permite reconhecê-lo quer como pilar estruturante da própria arquitetura educativa, quer como território de lutas pela 
hegemonia, quer, ainda, como esteio de relações sociais nem sempre visíveis mas que interferem tanto na legitimação de um determinado currículo nacional, organizado a partir de um conhecimento oficial tido como conhecimento válido (Apple, 1999)² , quanto na produção de identidades sociais particulares que determinam, em grande parte, a inclusão ou exclusão dos indivíduos na escola e, posteriormente, na sociedade. Currículo e conhecimento surgem, assim, em simultâneo, como produtos e produtores de relações sociais, num processo que não é imune aos interesses de determinados indivíduos e grupos específicos (Silva, 2002), que tendem a alcançar um protagonismo educativo em tudo idêntico ao poder e influência que detêm na sociedade.

19 A este respeito, importa referir, num breve relance histórico, a contaminação ideológica que tem impregnado essa relação, identificada por Louis Althusser, em 1983, na obra A Ideologia e os Aparelhos Ideológicos do Estado, onde o autor desmistifica o carácter desinteressado da transmissão do conhecimento na/pela escola e demonstra que a educação é um dispositivo propício para as classes dominantes veicularem as suas ideias e visões do mundo, garantindo, assim, a reprodução de uma dada cultura e a perpetuação da estrutura social vigente. Pese embora a realização de estudos posteriores permitisse reforçar e aprofundar a ligação do conceito de ideologia às relações de poder e às questões de interesse que pululam na sociedade, bem como compreender como é que "o conhecimento transmutado em currículo escolar atua para produzir identidades individuais e sociais no interior das instituições escolares" (Moreira e Silva, 2005: 25-26) e quem beneficia com essa transmutação, os trabalhos de Althusser foram marcantes e tiveram o mérito de iniciar um debate que continua bem vivo entre nós e se justifica pelo facto de o currículo que tem pontuado nas últimas décadas resultar, essencialmente, de uma tradição seletiva, no âmbito da qual certos grupos têm definido o conhecimento considerado como mais legítimo, "enquanto o conhecimento de outros raramente consegue ver a luz do dia", o que é revelador de quem tem o poder na sociedade (Apple, 1999: 51).

20 Para além da ideologia, a cultura é outro referente fundamental na configuração do currículo. Não podendo apenas ser vista, como se advogava no pensamento mais convencional, "como um conjunto inerte e estático de valores e conhecimentos a serem transmitidos de forma não-problemática a uma nova geração" (Moreira e Silva, 2005: 26), a cultura é hoje reconhecida como um elemento estruturante na conceção e desenvolvimento do currículo, uma vez que o molda e, em simultâneo, é moldada por ele. Daí o seu carácter eminentemente político e a possibilidade de contribuir para melhorar, ou debilitar, a coesão social. Todavia, ainda que através do currículo oficial se augure a transmissão de um dado conhecimento e a consolidação de uma dada cultura, importa sinalizar que o currículo jamais se restringe a um papel meramente transmissivo.

21 A sua concretização prática ocorre num "contexto cultural de [res]significação ativa dos materiais recebidos" e, por isso, de produção e criação de sentidos e significações, sendo a própria cultura vista, por inúmeros autores, "menos como uma coisa e mais como um campo e terreno de luta" (ibid:: 27).

22 Em suma, ideologia e cultura configuram-se, assim, como determinantes curriculares poderosos na base dos quais se estrutura tanto o conhecimento que a escola veicula, quanto as relações de poder e desigualdade que se geram no seu interior e que perpassam a própria educação e a sociedade em geral. Daí a necessidade de problematizar as relações sociais e históricas que têm gerado privilégios de uns e desconforto e sofrimento de outros e que refletem as lógicas de divisão e exclusão em torno das quais foram 
construídas, bem como de interpelar, continuamente, a própria construção curricular, uma vez que, como assevera Tomás da Silva (2002: 67), "a nossa identidade social é produzida histórica e socialmente não apenas no interior da escola mas no contexto de processos pedagógicos e formativos mais amplos". Assim se compreende, por um lado, a magnitude formativa do currículo e o papel que, de forma visível ou mais oculta, desempenha na produção e reprodução de relações sociais e na configuração de determinadas identidades, e, por outro, a influência de cada contexto específico no interior da instituição educativa, com efeitos tanto ao nível dos discursos como das práticas que aí se desenvolvem. No fundo, existe uma clara propensão de pedagogizar a política, a que se contrapõe uma clara tendência de politizar a pedagogia, numa dialética que condiciona a nossa visão do mundo e interfere na forma como nos posicionamos perante uma determinada realidade. Dito de outra forma, se o pedagógico e o escolar se revestem de indiscutíveis potencialidades culturais e formativas, não menos importante é o facto de "o cultural e o social [serem] pedagógicos e curriculares" e forjarem complexas relações que nos permitem compreender "as categorias de divisão social pelas quais nós e os outros somos posicionados" (ibid.: 67-68).

Nesta ordem de ideias, e no seguimento do desafio que colocámos no segmento anterior saber como descolonizar o pensamento e a produção de conhecimento -, importa problematizar se os curricula desenvolvidos nas últimas décadas têm sido espaços de verdadeira vivência democrática, isto é, esteios de diferenciação pedagógica e veículos de desenvolvimento e integração pessoal e social de estudantes oriundos de contextos socioculturais distintos; ou se, pelo contrário, se têm limitado a transmitir e a legitimar o conhecimento que se considera útil que os alunos aprendam na escola e a difundir determinadas ideologias e políticas dominantes, em detrimento de outras igualmente válidas e importantes. Mais concretamente no contexto português, importa averiguar se, com o fi $\mathrm{m}$ do regime ditatorial e do colonialismo político e a instauração do regime democrático, o currículo se eximiu da dominação epistemológica que exerceu durante décadas e se libertou das amarras ao seu passado colonial, reparando danos e efeitos menos desejáveis, ou se, como afi rma Anibal Quijano (2010), essas marcas se perpetuaram, agora na forma de colonialidade de poder e saber, não apenas em termos externos mas nas relações internas entre diferentes grupos sociais do país.

Não deixando de reconhecer, ao nível dos discursos políticos, a necessidade de construir uma escola mais inclusiva, só possível através da consecução de um currículo mais democrático, o que se verifica é que, na prática, o currículo tem privilegiado a afirmação de determinados valores e a passagem de certos conhecimentos, que Michael Apple (1999) designa como conhecimento oficial, que expressam os pontos de vista e os interesses de grupos socialmente dominantes e permitem, nem sempre de forma explícita, legitimar "a ordem social construída" (Silva, 2002: 68) e perpetuar os privilégios de certas elites. Confirma-se, assim, a desconfiança de Sandra Harding (2000) de que, sob a égide da democratização do saber e do diálogo entre diferentes conhecimentos, se tem sobretudo afirmado uma epistemologia dominante (Santos e Meneses, 2010) que privilegia a passagem de determinados saberes em detrimento de outros. Uma situação que, em nosso entender, tem contribuído de forma significativa para inquinar todo o processo de democratização do ensino e está na base do elevado insucesso escolar que grassa em muitos países. Além disso, esta situação de dominância epistemológica permite confirmar um outro aspeto sobejamente investigado: o facto de o meio social de proveniência interferir nos percursos escolares dos estudantes e se relacionar com o seu êxito na 
escola, explicando assim os níveis de insucesso típicos de certas minorias e/ou classes mais desfavorecidas. A este respeito, as palavras de José Soeiro (2008) são sintomáticas:

A escola fabrica várias formas de exclusão. Não deixa entrar os que estão fora e esse é o problema do acesso. Põe fora os que estão dentro - e aí estamos perante o drama do insucesso escolar e do abandono. Exclui incluindo - a forma escolar é em si uniformizadora e adversa à diversidade. $\mathrm{E}$, num certo sentido, a inclusão na escola deixou de fazer sentido, porque é difícil perceber para que é que precisamos de lá estar. A cada um destes problemas - o acesso, o sucesso, a diversidade dos públicos escolares e o sentido do trabalho escolar - nós só podemos responder com uma escolha: mais e melhor democracia.

Aos aspetos referidos não podemos deixar de associar o facto de a escola pública, no contexto da globalização e das reformas neoliberais a que tem estado sujeita mais recentemente, se ter transformado num "objeto de operosa mobilização política, social e pedagógica", sujeita a disputas e em permanente escrutínio, na tentativa de identificar o que se considera ser "uma boa escola, um bom conhecimento, um bom ensino e uma boa aprendizagem" (Diniz, 2012: 8). Essa situação não pode dissociar-se das políticas educativas e curriculares vigentes que, sob a égide da melhoria do serviço público de educação, têm pretendido sobretudo redimensionar o sistema educativo em função de modelos alternativos de regulação e provisão do serviço educativo. No fundo, um conjunto de medidas e mudanças políticas associadas a propósitos e valores próprios da economia que, "em vez de curar", têm servido essencialmente para renovar o controlo oficial do sistema, introduzir "novas formas de incerteza e insegurança" e gerar "sentimentos de heteronomia profissional" (Sanches, 2009: 128). Fundadas na base de lógicas hierarquizantes e na procura imediata de níveis de qualidade mais elevados, as atuais políticas educativas contemporâneas têm gerado uma clara obsessão normativa e uma "estandardização insensível" (Hargreaves, 2003: 118), bem como uma engenharia curricular propulsora de perspetivas mais tecnicistas de ensino, relegando os professores para funções meramente executivas. Os aspetos referidos interferem na forma como os professores organizam e concretizam os processos de ensino-aprendizagem, sobretudo porque continuamos a trabalhar com um currículo estruturado numa perspetiva claramente colonizadora.

Impõe-se, por isso, refletir em torno das seguintes questões: O que será possível fazer para inverter esta situação? Como construir um currículo que permita, na prática quotidiana da escola e, em particular, da sala de aulas, envolver e dar voz aos estudantes, independentemente da sua condição social e cultural? Como desenvolver processos educativos que elejam a pessoa como centro de toda a ação educativa e façam da inclusão, da solidariedade, da compreensão, da cidadania, da liberdade, da democracia e do respeito pela natureza, imperativos essenciais para compreender melhor o mundo?

\section{A descolonização do currículo}

Como constatámos no segmento anterior, a escola pública encontra-se hoje numa encruzilhada, dada a confluência de influências políticas, sociais e económicas a que tem estado sujeita e que a têm vinculado à produção e disseminação de códigos culturais hegemónicos e à consequente promoção de elites, numa lógica que espelha de forma límpida a sociedade em que se integra e lhe permite existência. Uma sociedade onde, por via do vendaval globalizador que a tem assolado, das intensas reformas de feição neoliberal que têm eclodido no seu interior e do progresso do capitalismo global, as 
diferenças culturais e políticas se acentuaram e assenta na ideia do que Boaventura Santos (2010) designa por pensamento abissal, para se referir a um pensamento que se funda numa separação dos atores, das experiências e dos saberes entre os que são inteligíveis e úteis e os que se configuram como ininteligíveis e inúteis, sendo, por isso, votados ao esquecimento e concomitante supressão. $O$ mais preocupante é o currículo estar imbuído desta separação e, de forma mais ou menos explícita, interferir com as práticas pedagógicas que se desenvolvem na escola.

28 A reversão desta tendência não é fácil, sobretudo quando muitos dos argumentos que poderiam invertê-la residem fora da instituição educativa. Demonstram-no as políticas educativas mais recentes que, a pretexto de uma "imaginada" modernização, têm estimulado a iniciativa privada e subjugado o sistema educativo ao mundo do trabalho e aos imperativos da produtividade económica, agravando as desigualdades sociais e fragilizando um dos princípios que deve nortear o ensino público em qualquer sociedade democrática, só possível de concretizar através de uma efetiva integração e inclusão dos mais desfavorecidos: a igualdade de oportunidades.

No entanto, ainda que a alteração deste cenário exija uma mudança política e uma postura menos centralizadora por parte da administração educativa - com a consequente concessão de maiores competências curriculares à escola e aos professores e a criação de condições que impliquem os diversos agentes educativos em estratégias que viabilizem mudanças tanto a nível das práticas como da própria cultura escolar (Morgado, 2013) -, essa transformação só será uma realidade se os professores se apropriarem do verdadeiro sentido das mudanças que estão ao seu alcance, utilizarem as competências que lhes estão consignadas e se assumirem como verdadeiros decisores curriculares.

Se consideramos que a educação deve continuar a propor modelos de se humano e de sociedade, sem se limitar a adaptar às demandas do momento (o que não significa desconsiderá-las), não podemos ficar à espera do que nos seja demandado do exterior e reclamado pelo mercado, mas devemos defender determinada atitude comprometida com um projeto democraticamente elaborado, que sirva a um modelo flexível de indivíduo e de sociedade. (Gimeno, 2008: 75-76)

Dito de outra forma, é imprescindível que se desencadeie uma progressiva descolonização do currículo, transformando-o numa construção participada e numa partilha assumida de poderes e responsabilidades, permitindo que os intervenientes no processo educativo se envolvam na (re)formulação das políticas de ensino e na conceção e concretização de um projeto formativo comum (Morgado, 2013). No fundo, que seja assumido como projeto e prática participada, criando condições para que os grupos socialmente subordinados possam expressar os seus pontos de vista e contestar os conhecimentos e os significados que o currículo tem privilegiado. Para que isso seja viável, existem, pelo menos, três alterações que consideramos cruciais.

Em primeiro lugar, que se reate a ligação teoria-prática, progressivamente debilitada pela separação entre os que teorizam e os que praticam a educação. Muito do que os professores hoje fazem na escola é decidido no seu exterior, compelindo-os a assumir posturas demasiado transmissivas e a desqualificar os saberes da prática, essenciais para contraditar os conhecimentos que o currículo oficial veicula. Aí reside a possibilidade de transformar o conhecimento científico em conhecimento escolar, mais acessível e mais próximo dos estudantes. Além disso, é o confronto desses distintos saberes, isto é, o cruzamento do popular e do erudito, que transforma a sala de aulas num espaço de ressignificação e produção de novos conhecimentos, essenciais para a construção de 
novas possibilidades de compreensão do mundo e da forma como cada um se (re)vê a si mesmo e aos outros (Garcia \& Moreira, 2008). Para que estas mudanças se concretizem, é necessário que se cumpram dois pressupostos. Por um lado, é preciso assumir o currículo como um instrumento flexível e integrador e valorizar, como sugere Boaventura de Sousa Santos (1999: 199), a existência de currículos informais, garantindo assim que a instituição educativa se transforme num espaço privilegiado de "encontro de saberes", que, sem descurar o saber científico que aí se produz e transmite, valoriza, em igual medida, os saberes não científicos. Por outro lado, é necessário alterar profundamente a formação (inicial e contínua) dos professores. Neste domínio, a prevalência de uma cultura de performatividade, fundada numa "gramática" e numa "semântica" que não são neutras e enfatizam a importância de "processos de gestão cada vez mais sofisticados e de sistemas de medidas de resultados" (Candau, 2013: 13), tem veiculado um profissionalismo controlado, relegando os professores para o papel de meros executantes das orientações gerais das políticas educativas (Canário, 2008).

Em segundo lugar, uma eventual descolonização do currículo requer que os professores elaborem os materiais curriculares que utilizam nas aulas e recorram a novos textos, de cariz contra-hegemónico e integrador, eximindo-se, assim, de se cingir à utilização dos materiais curriculares oficiais. Na maioria dos casos, estes materiais - livros de texto, manuais escolares, cadernos de fichas de trabalho... - não se afirmam como meios de interpelação e questionamento dos saberes, mas como meros instrumentos de transmissão de conhecimentos, académica e institucionalmente reconhecidos como válidos. Daí a necessidade de os professores não subordinarem a tarefa docente ao estipulado nesses materiais, sob pena de entrarem numa rota de progressiva desprofissionalização. Quando essa substituição não for possível, Silva (2002: 69) sugere que "os materiais existentes, claramente enviesados e interessados, [constituam] matériaprima a partir da qual os significados, as visões e as representações dominantes [possam] ser contestados, desafiados e resistidos".

Por último, a descolonização do currículo exige que as tarefas educativas envolvam debate e reflexão e se centrem em questões e problemas do mundo contemporâneo como, por exemplo, o papel e o valor da ciência, o desemprego estrutural, a pobreza, o isolamento social, o racismo, as desigualdades sociais e económicas, a hibridação cultural, os conflitos étnicos e culturais, a violência, a homofobia, o sexismo, as crenças religiosas, as interdependências, a segurança, entre outros -, permitindo, assim, "considerar as representações mentais dos indivíduos, as ideias sobre o outro, o entendimento das situações humanas de conflito, as imagens que elaboramos de nós próprios em relação aos outros" (Gimeno, 2008: 49). Só com um currículo aberto, que não se restrinja à mera passagem dos saberes científicos, e com o envolvimento dos distintos grupos que participam no processo educacional será possível transformar as salas de aula em efetivos locus de produção de conhecimentos e contestar os significados e as representações que têm dominado o fenómeno educativo. No fundo, um currículo que potencia um modelo educativo que estimula a participação, a discussão e a negociação e que, numa perspetiva dialética, faz do conflito e da crítica verdadeiras oportunidades de aprendizagem.

\section{Considerações finais}

34 Não a um pensamento hegemónico. Não a um sistema educativo pouco democrático. Não à clausura de saberes que permitem o acesso a uma leitura plurividente da riqueza das 
experiências sociais, culturais, históricas e políticas existentes. Não à rasura de conhecimentos que validam a nossa luta pela igualdade e pela partilha lúcida de deveres e direitos civis perante esse grande pilar da experiência humana e maior: a humanidade que pensa e se estrutura vigilante dos seus caminhos.

Este artigo pretendeu, com os seus rasgos desobedientes e reflexões críticas, percorrer um dos muitos ângulos de trabalho, de questionamento e de intervenção que as Epistemologias do Sul no contexto português de investigação permitem definir e identificar, no sentido de demonstrar que as escolhas da investigação, respeitando os seus vários contextos de trabalho, são capazes de trazer para o pensamento de todos, com argúcia, os lugares mais silenciosos e as vozes e palavras que completarão o mundo da diversidade humana.

\section{BIBLIOGRAPHY}

APPLE, M. (1999), Políticas Culturais e Educação. Porto: Porto Editora.

ARAÚJO, Marta; RODRÍGUEZ MAESO, Silvia (2010), “Explorando o eurocentrismo nos manuais portugueses de História”, in Estudos de Sociologia, V. 15, 28: 239-270.

ARAÚJO, Marta; RODRÍGUEZ MAESO, Silvia (2011), “Institucionalização do silêncio: A escravatura nos manuais de história portugueses”, in Revista/Ensino Superior, Revista SNESup,39: 1-10.

ARAÚJO, Marta; RODRÍGUEZ MAESO, Silvia (2013), “A presença ausente do racial: discursos políticos e pedagógicos sobre História, 'Portugal' e (pós-colonialismo)”, in Educar em Revista, 47: 145-171.

BARNES, Colin (2003), “What a difference a decade makes: Refl ections on doing 'Emancipatory' disability research", in Disability \& Society, 18 (1): 3-17.

BURAWOY, M. (2008), “Rejoinder: For a subaltern global sociology”, in Current Sociology, 56(3): 435-444.

CANÁRIO, R. (2008), "Formação e desenvolvimento profissional dos professores”, in Ministério da Educação (org.), Conferência Desenvolvimento profissional de professores para a qualidade e para a equidade da Aprendizagem ao longo da Vida. Lisboa: Ministério da Educação.

CANDAU, V. (2013), “Currículo, didática e formação de professores: uma teia de ideias-força e perspetivas de futuro”, in M. R. Oliveira \& J. A. Pacheco (orgs.), Currículo, Didática e Formação de Professores. Campinas, São Paulo: Papirus Editora, 7-19.

CASSANO, Franco (2010), “South of every North”, in Encarnación G. Rodríguez; Manuela Boatca \& Sérgio Costa (eds.). Decolonizing European Sociology. Transdisciplinary Approaches. Farnham, Surrey: Ashgate: 213-224.

CHAKRABARTY, Dipesh (2000), Provicialinzing Europe: Postcolonial thought and historical difference. Princeton: Princeton University Press.

CONNELL, Raewyn (2007), Southern Theory. Cambridge: Polity Press. 
DINIZ, A. V. (2012), “Prefácio”, in M. Z. Pereira \& I. S. Lima (orgs.), Currículo e Políticas Educacionais em Debate. Campinas, São Paulo: Editora Alínea: 7-11.

DUSSEL, Enrique (2000), “Europe, modernity and eurocentrism”, in Neplanta: Views from South, 1.3: $465-478$.

FRANK, André Gunder (1961), Desenvolvimento e subdesenvolvimento. Rio de Janeiro: Fundo de Cultura.

FURTADO, Celso (1961), Desenvolvimento e subdesenvolvimento. Rio de Janeiro: Fundo de Cultura.

GARCIA, R. L. \& MOREIRA, A. F. (2008), “Começando uma conversa sobre currículo”, in R. L. Garcia \& A. F. Moreira (orgs.), Currículo na contemporaneidade: incertezas e desafios. São Paulo: Cortez Editora, 7-39.

GIMENO, J. (2008), “O significado e a função da educação na sociedade e na cultura globalizadas”, in R. L. Garcia \& A. F. Moreira (rgs.), Currículo na contemporaneidade: incertezas e desafios. São Paulo: Cortez Editora, 41-80.

HARDING, Sandra (2000), "Should philosophies of science encode democratic ideals", in Daniel Kleinman (org.), Science, Technology and Democracy. New York: State University of New York Press: 121-138.

HARGREAVES, A. (2003), o Ensino na Sociedade do conhecimento: A educação na era da insegurança. Porto: Porto Editora.

HOSELITZ, B.F. (1960), The Sociological Aspects of Economic Growth. Chicago: Free Press, Illinois, The Free Press of Glencoe.

HOUNTONDJI, Paulin J. (2002), "Knowledge appropriation in a post-colonial context", in Catherine A. Odora Hoppers (ed.). Indigenous Knowledge and the Integration of Knowledge Systems. South Africa: New Africa Books: 23-38.

KHAN, Sheila (2011), “O ‘Sul' mesmo aqui ao lado: cartografi as identitárias abissais no póscolonialismo português”, in Brandão, Ana Maria e Araújo, Emília Rodrigues (orgs.). Intersecções Identitárias. Famalicão: Edições Húmus, 49-64.

LANDER, Edgardo (2000), "Eurocentrism and Colonialism in Latin America Social Thought", in Neplanta: Views from South, 1.3: 519-532.

LOPES, H. (2009), Crónicas Africanas. Porto: Edições Afrontamento.

LOURENÇO, Eduardo (2011), A Europa Desencantada. Para uma mitologia europeia. Lisboa: Gradiva.

MARTINS, Bruno Sena (2013), Sentido Sul: A cegueira no espírito do lugar. Coimbra: Almedina.

MARTINS, Bruno Sena; FONTES, Fernando; HESPANHA, Pedro \& BERG, Aleksandra (2012), “A emancipação dos estudos da deficiência”, in Revista Crítica de Ciências Sociais, 98, setembro, 45-64.

MENESES, Paula (2012), "Bodies of violence, languages of resistance”, in Sheila Khan; Hilary Owen; Ana Margarida Dias Martins \& Carmen Ramos Villar (eds.), “The Lusotropical Tempest: Postcolonial Debates in Portuguese", in Lusophone Studies, 7, Bristol University: 75-114.

MIGNOLO, Walter D. (2007), “Delinking”, in Cultural Studies, 21:2: 449-514.

MIGNOLO, Walter D. (2009), "Epistemic disobedience, independent thought and decolonial freedom", in Theory, Culture \& Society, vol. 26 (7-8): 159-181.

MIGNOLO, Walter D. (2011), The Darker Side of Western Modernity. Global cultures, decolonial options. Durham/London: Duke University Press. 
MOREIRA, A. F. \& SILVA, T. T. (2005), "Sociologia e teoria crítica do currículo: uma introdução", in A. F. Moreira \& T. T. da Silva (orgs.), Currículo, Cultura e Sociedade. São Paulo: Cortez Editora: 7-37. MORGADO, J. C. (2003), "Processos e práticas de (re)construção da autonomia curricular". Tese de Doutoramento. Braga: Universidade do Minho (policopiado).

MORGADO, J. C. (2004), Manuais Escolares. Contributo para uma análise. Porto: Porto Editora.

MORGADO, J. C. (2013), “Democratizar a escola através do currículo”, in Ensaio: Avaliação e Políticas Públicas em Educação, 21 (80): 433-448.

MYRDAL, Gunnar [1974 (1957)], Teoria económica e regiões subdesenvolvidas. Rio de Janeiro: Edição Paz e Terra.

OLIVER, Michael (1997), “Emancipatory Research: Realistic Goal or Impossible Dream?”, in Colin Barnes \& Geof Mercer (orgs.), Doing Disability Research. Leeds: The Disability Press, 15-31.

ROSTOW, W. [1964 (1959)], Etapas do desenvolvimento económico. Rio de Janeiro: Zahar Editores.

SANCHES, M. F. (2009), “'(In)sustentável leveza' da liderança dos professores em contextos de mudança: contrastes entre idealidade e realidade", in M. F. Sanches (org.), A Escola como Espaço Social: Leituras e olhares de professores e alunos. Porto: Porto Editora, 125-162.

SANTOS, B. S. \& MENESES, M. P. (2010), “Introdução”, in B. S. Santos \& M. P. Meneses (orgs.), Epistemologias do Sul. Coimbra: Edições Almedina, 9-20.

SANTOS, B. S. (1999), Pela Mão de Alice: O social e o político na pós-modernidade. Porto: Edições Afrontamento.

SANTOS, B. S. (2010), “Um Ocidente não-ocidentalista? A filosofia à venda, a douta ignorância e a aposta de Pascal”, in B. S. Santos \& M. P. Meneses (orgs.), Epistemologias do Sul. Coimbra: Edições Almedina, 467-507.

SANTOS, B. S. (1985), "Estado e Sociedade na semiperiferia do sistema mundial: o caso português”, in Análise Social, XXI, 87-88-89: 869-901.

SANTOS, B. S. (2007), "Para além do Pensamento Abissal: Das linhas globais a uma ecologia de saberes", in Revista Crítica de Ciências Sociais, 78: 3-46.

SANTOS, B. S. (2011), Portugal, Ensaio contra a Autoflagelação. Coimbra: Edições Almedina.

SILVA, Manuel Carlos \& CARDOSO, António (2005), “O local face ao global: por uma revisitação crítica dos modelos de desenvolvimento" in M. C. Silva; A. P. Marques, \& R. Cabecinhas, (orgs.), Desenvolvimento e Assimetrias Sócio-espaciais. Perspectivas teóricas e estudos de caso. Braga: Núcleo de Estudos em Sociologia/Universidade do Minho, 23-79.

SILVA, T. T. (2002), "Descolonizar o currículo: estratégias para uma pedagogia crítica”, in M. V. Costa (org.), Escola Básica na Virada do Século: Cultura, política e currículo. São Paulo: Cortez Editora, 61-72.

SMITH, Linda Tuhiwai (1999), Decolonizing Methodologies: Research and indigenous peoples. London: Zed Books.

SOEIRO, J. (2008), A Defesa da Escola Pública e Democrática. Intervenção na sessão parlamentar de comemoração do 25 de Abril. Disponível em: http://beparlamento.esquerda.net. Acesso em 10.jul.2012.

WALLERSTEIN, Immanuel [1990 (1974)], O Sistema Económico Mundial. Porto: Afrontamento. 


\section{NOTES}

1. Músico e compositor português, excerto da música "Atrás dos tempos outros tempos vêm”, do álbum Madrugada dos Trapeiros (1977).

2. Na opinião do autor, o problema não é a existência de um currículo oficial, nem de um conhecimento oficial. o problema é a forma e o conteúdo desse currículo funcionarem "como indicadores de classe", concorrendo para transformar a escola "numa escola de classes" que reproduz as "relações desiguais de poder" que existem na sociedade (Apple, 1999: 52).

\section{ABSTRACTS}

Este artigo pretende pensar de uma maneira crítica a construção, difusão e validação do currículo. As reflexões aqui apresentadas constituem uma leitura analítica, no sentido de demonstrar que a construção dos curricula e seus produtos finais, tais como muitos manuais escolares, permanecem como ferramentas e dispositivos ainda ancorados numa lógica de pensamento ocidental, monocultural e limitado na nossa visão cultural da experiência humana.

This article takes a critical look at the construction, validation and dissemination of the curriculum. The reflections presented are an analytical reading in that they show that the construction of curricula and their final products, such as textbooks, endure as tools and devices, still anchored to a logic of monocultural Western thought that is limited in its cultural view of human experience.

Cet article se propose de réfléchir d'une manière critique sur la construction, la validation et la diffusion du programme. Les réflexions présentées ici sont une lecture analytique permettant de démontrer que la construction des programmes et leurs produits finis, tels que les manuels, restent des outils et des dispositifs qui sont toujours fondés sur une logique de pensée occidentale monoculturelle et limitée à notre vision culturelle de l'expérience humaine.

\section{INDEX}

Mots-clés: épistémologies du Sud, la pensée occidentale, programme, décolonisation de la pensée

Palavras-chave: Epistemologias do Sul, pensamento ocidental, currículo, descolonização do pensamento

Keywords: Epistemologies of the South, Western thought, curriculum, decolonization of thought 


\section{AUTHORS}

\section{SHEILA KHAN}

Centro de Investigação em Ciências Sociais, Universidade do Minho sheilakhan31@gmail.com

\section{JOSÉ CARLOS MORGADO}

Instituto de Educação. Universidade do Minho

jmorgado@ie.uminho.pt 